\title{
APC2 Plays an Essential Role in Axonal Projections through the Regulation of Microtubule Stability
}

\author{
Takafumi Shintani, ${ }^{1,2}$ Masaru Ihara, ${ }^{1}$ Sachiko Tani, ${ }^{1,2}$ Juichi Sakuraba, ${ }^{1,2}$ Hiraki Sakuta, ${ }^{1,2}$ and Masaharu Noda ${ }^{1,2}$ \\ ${ }^{1}$ Division of Molecular Neurobiology, National Institute for Basic Biology, and ${ }^{2}$ School of Life Science, The Graduate University for Advanced Studies, \\ Okazaki 444-8787, Japan
}

Growth cones at the tip of growing axons are key cellular structures that detect guidance cues and mediate axonal growth. An increasing number of studies have suggested that the dynamic regulation of microtubules in the growth cone plays an essential role in growth cone steering. The dynamic properties of microtubules are considered to be regulated by variegated cellular factors but, in particular, through microtubule-interacting proteins. Here, we examined the functional role of adenomatous polyposis coli-like molecule 2 (APC2) in the development of axonal projections by using the chick retinotectal topographic projection system. APC2 is preferentially expressed in the nervous system from early developmental stages through to adulthood. Immunohistochemical analysis revealed that APC2 is distributed along microtubules in growth cones as well as axon shafts of retinal axons. Overexpression of APC2 in cultured cells induced the stabilization of microtubules, whereas the knockdown of $A P C 2$ in chick retinas with specific short hairpin RNA reduced the stability of microtubules in retinal axons. APC2 knockdown retinal axons showed abnormal growth attributable to a reduced response to ephrin- $\mathrm{A} 2$ in vitro. Furthermore, they showed drastic alterations in retinotectal projections without making clear target zones in the tectum in vivo. These results suggest that APC2 plays a critical role in the development of the nervous system through the regulation of microtubule stability.

\section{Introduction}

In the developing nervous system, axons are directed to their targets by extracellular guidance molecules, either permissive (attractive) or inhibitory (repulsive). Growth cones at the tips of growing axons are key cellular structures that detect guidance cues and mediate axon growth in the proper direction. In growth cones, actin filaments and microtubules are major cytoskeletal constituents whose organization changes dynamically. It is believed that the actin cytoskeleton is primarily responsible for initiating and directing growth cone steering, whereas microtubules consolidate and support the new extension induced by the actin activity (Mitchison and Kirschner, 1988; Smith, 1988). However, an increasing number of studies have recently suggested that dynamic microtubules in the growth cone play a critical role in growth cone steering. During growth and navigation of the axon, the microtubule array within the growth cone is repeatedly reorganized and reorients toward the future direction of axon outgrowth (Sabry et al., 1991; Tanaka and Kirschner, 1991; Tanaka and Kirschner, 1995; Tanaka and Sabry, 1995; Suter et al., 1998). In addition, inhibition of microtubule dynamics with pharmacological agents abolished the turning behavior, and localized stabilization and destabilization of microtubules are sufficient to

Received May 21, 2009; revised July 23, 2009; accepted Aug. 5, 2009.

This work was supported by grants from the Ministry of Education, Culture, Sports, Science, and Technology of Japan. We thank Dr. Y. Mimori-Kiyosue (Kan Research Institute, Kobe, Japan) for technical advice. We also thank S. Miura, N. Hattori, and M. Mizoguchi for technical assistance and A. Kodama for secretarial assistance.

Corresponding should be addressed to Dr. Masaharu Noda, Division of Molecular Neurobiology, National Institute for Basic Biology, 5-1 Higashiyama, Myodaiji-cho, 0kazaki 444-8787, Japan. E-mail: madon@nibb.ac.jp. DOI:10.1523/JNEUROSCI.2394-09.2009

Copyright $\odot 2009$ Society for Neuroscience ～0270-6474/09/2911628-13\$15.00/0 induce attractive and repulsive turning (Williamson et al., 1996; Challacombe et al., 1997; Buck and Zheng, 2002).

The dynamic properties of microtubules are considered to be regulated by diverse cellular factors, in particular by microtubuleinteracting proteins including microtubule-associated proteins (MAPs) and plus-end tracking proteins (+TIPs) (Matus, 1990; Hirokawa, 1994; Kalil and Dent, 2005). MAPs have been shown to play important roles in promoting the assembly of tubulins into microtubules and the stabilization of formed microtubules. On the other hand, +TIPs bind selectively to the plus ends of microtubules and contribute to their stabilization by reducing the frequency of microtubule shortening or by promoting their growth. One well characterized + TIP is adenomatous polyposis coli (APC), originally identified as a tumor suppressor mutated in familial colon cancers. APC has been reported to bind directly to microtubules through its $\mathrm{COOH}(\mathrm{C})$-terminal basic region to stabilize them (Munemitsu et al., 1994; Mimori-Kiyosue et al., 2000; Zumbrunn et al., 2001). It has been shown that APC modulates axon steering in vitro (Koester et al., 2007). Moreover, APC is reportedly implicated in the development of the cerebral cortex (Yokota et al., 2009). In the APC family, a second APC-like molecule, APC2/APCL, has been identified (Nakagawa et al., 1998). Their central portion, containing armadillo repeats and the $\beta$-catenin binding region, is fairly conserved, but their C-terminal region diversifies significantly (see Fig. $1 A$ ). APC2 is known to be expressed preferentially in the CNS in mice (Yamanaka et al., 2002), but its physiological function in vivo remains unknown.

The present study was undertaken to elucidate the function of APC2 in axonal projection. We found that APC2 is distributed along microtubules in growth cones as well as axon shafts and implicated in the regulation of microtubule stability. Using the 


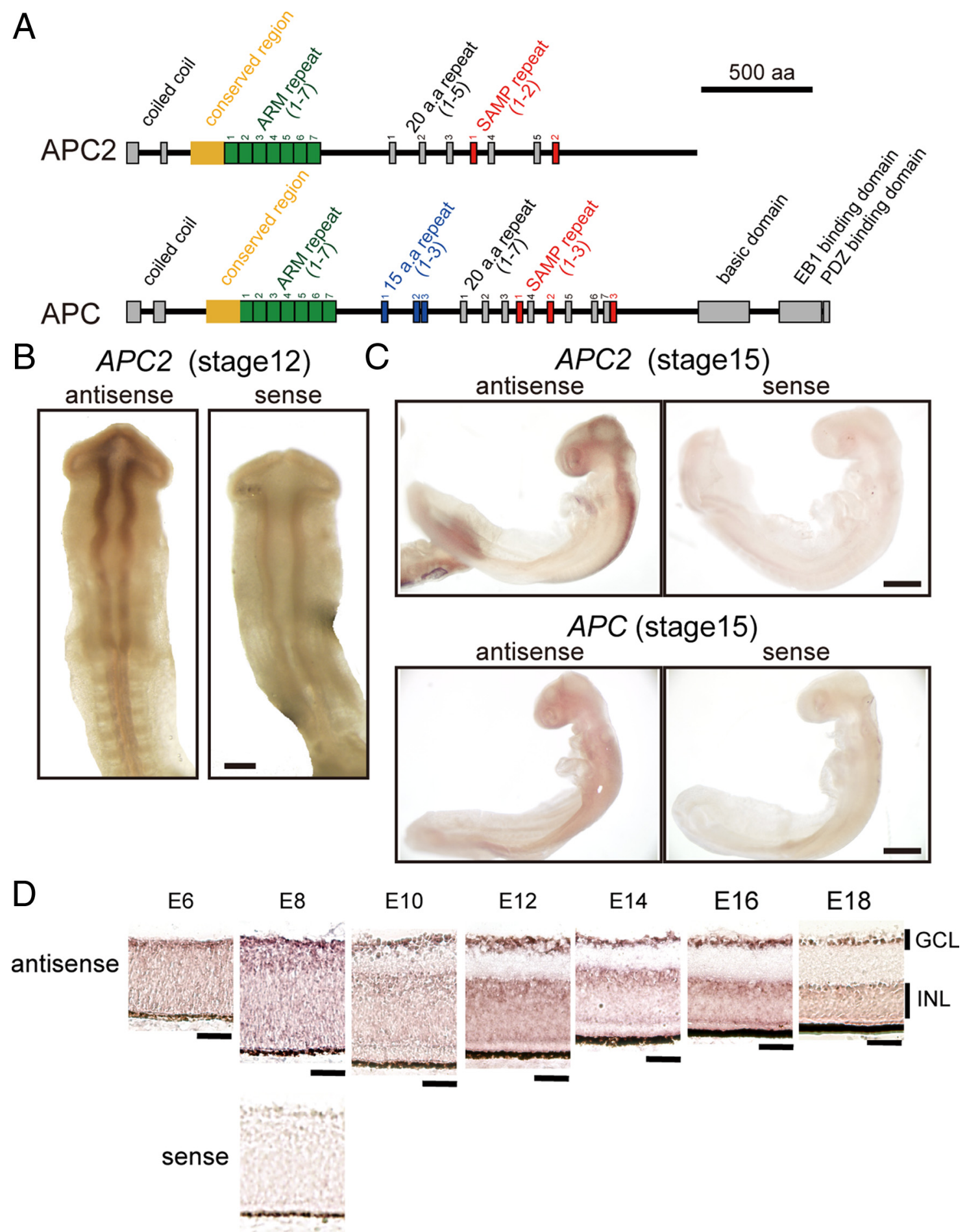

Figure 1. Comparison of the structure and expression patterns between $A P C 2$ and $A P C$ in chick embryos. $A$, Schematic representation of the structure of the $A P C 2$ and $A P C$ proteins. APC2 and $A P C$ harbor similar N-terminal dimerization domains, conserved domains, armadillo repeats, $\beta$-catenin-binding 20 aa repeats, and axin-binding SAMP repeats. However, they are less conserved at the C terminus: APC contains a microtubule-binding basic domain, EB1-binding domain, and a PDZ (postsynaptic density-95/Discs large/zona occludens-1)-binding motif at the C terminus. In addition, 15 aa repeats of $A P C$ are also known to bind $\beta$-catenin. $B$, C, Whole-mount in situ hybridization analysis of $A P C 2$ and $A P C$ in chick embryos. Dorsal view of whole-mount in situ hybridization of HH stage 12 embryos and lateral view of $\mathrm{HH}$ stage 15 embryos. $A P C 2$ expression is observed at the neural tube at stage 12 , and $A P C 2$ is expressed selectively in the nervous system. In contrast, a low level of $A P C$ expression is observed broadly in the whole embryonic body of $\mathrm{HH}$ stage 15 embryos. Scale bars: stage $12,250 \mu \mathrm{m}$; stage 15, $500 \mu \mathrm{m}$. D, Section in situ hybridization of $A P C 2$ in the developing retina. The control experiment with the sense probe is shown only for E8 retina. APC2 expression in the dorsocentral region of the retinas at E6, E8, E10, E12, E14, E16, and E18 is shown. A high level of $A P C 2$ expression is observed in the ganglion cell layer throughout E6 - 18. Scale bars, $50 \mu \mathrm{m}$. GCL, Ganglion cell layer; INL, inner nuclear layer.

topographic retinotectal projection system in chicks, we performed overexpression and knockdown experiments with APC2 in vitro and in vivo. Here, we demonstrate that APC2 is essential for the establishment of axonal projections.

\section{Materials and Methods}

Animals. White Leghorn chick embryos were maintained at $37.5^{\circ} \mathrm{C}$ in a humidified incubator. Chick embryos were staged according to Hamburger and Hamilton (1951). 
Antibodies. Anti-APC2 (L-17) and anti-APC (C-20) antibodies were purchased from Santa Cruz Biotechnology. Anti-myc, anti-Tuj1, and anti-acetylated tubulin antibodies were from Sigma. Anti-detyrosinated tubulin was from Millipore Bioscience Research Reagents. Anti$\alpha$-tubulin and anti-glyceraldehyde-3-phosphate dehydrogenase (GAPDH) HRP-conjugated antibodies were from Abcam. Anti-green fluorescent protein (GFP) antibody was from Nacalai. Alexaconjugated secondary antibodies were from Invitrogen.

In situ hybridization. In situ hybridization with whole embryos and tissue sections, image acquisition, and figure processing were performed as described previously (Suzuki et al., 2000). Templates used for the preparation of cRNA probes were as follows: chick APC2 (nucleotide residues 272-811; GenBank accession number GQ131429) and APC (nucleotide residues 2451-3082; GenBank accession number XM413974).

Immunohistochemistry. For immunostaining, embryos were fixed with $4 \%$ paraformaldehyde (PFA) in PBS overnight at $4^{\circ} \mathrm{C}$, rinsed in PBS, and infiltrated with a graded sucrose series to $18 \%$. The embryos were then embedded in OCT compound and sectioned at 12 $\mu \mathrm{m}$. The sectioned samples were treated with $0.1 \%$ Triton X-100 in Tris-buffered saline (TBS) for $5 \mathrm{~min}$ at room temperature and then incubated in blocking buffer (3\% skim milk in TBS) for $1 \mathrm{~h}$ at room temperature. Reactions with primary antibodies were performed for $2 \mathrm{~h}$ in a humidified chamber at room temperature. After being washed with TBS, the specimens were incubated with Alexa-conjugated secondary antibodies for $1 \mathrm{~h}$ at room temperature. Nuclear staining was performed using $4^{\prime}, 6^{\prime}$-diamidino-2-phenylindole at $0.05 \mu \mathrm{g} / \mathrm{ml}$. The fluorescent signals were observed with a Carl Zeiss Axioplan 2 microscope, and images obtained were processed using Adobe Photoshop 6 (Adobe Systems).

For immunohistochemistry on retinal flat mounts, the cornea and pigment epithelium were removed from isolated eyes, and the retina (photoreceptor layer down) was attached to a nylon filter (Hybond P; GE Healthcare) precoated with concanavalin A (Wako Pure Chemicals). Samples were treated the same as the sectioned samples.

DNA constructs. To prepare APC2-myc expression constructs, the full-length mouse and chick APC2 cDNAs were cloned using the total RNA from the postnatal day 0 mouse retinas and embryonic day 8 (E8) chick retinas as a template, respectively. The oligonucleotide sequences used for the construction were as follows: mouse APC2 forward, GAATTCACCATGGCCTCATATGAGCTGGTGCGCCAG; mouse APC2 reverse, GCGGCCGCTACTCCAGGAGACTGGCTGGAGAGGAGAC; chick APC2 forward, GAATTCACCATGTCCGGAGCGGCATCGTACGAGCAG; chick APC2 reverse, CTCGAGTCACGCCTGGATTTTCTCCACTGCTTTGTC. After being tagged with the myc-epitope sequence (EQKLISEEDL) at the $\mathrm{COOH}$ terminus by reverse transcription-PCR, the mouse and chick APC2 cDNA fragments were cloned into the expression vector pcDNA3.1 (Invitrogen) using EcoRI/NotI and EcoRI/XhoI sites, respectively. For overexpression of APC2, the chick construct was used unless otherwise indicated. Chick APC-myc expression construct
A

APC2

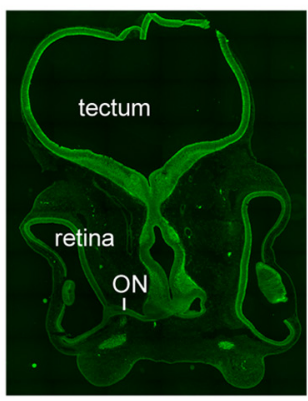

B

C

D

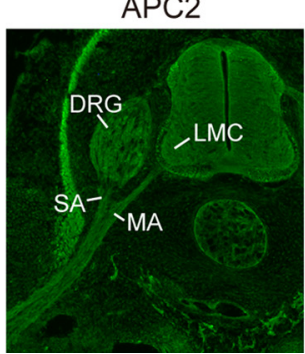

Tuj1

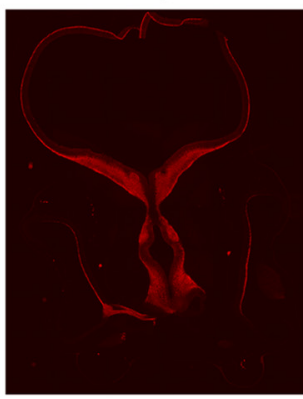

Tuj1

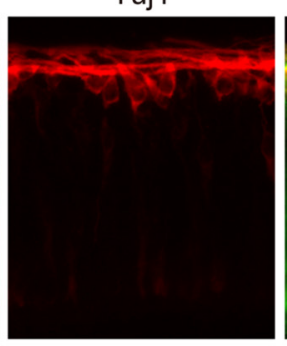

Tuj1

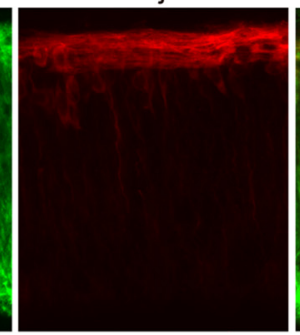

Tuj1

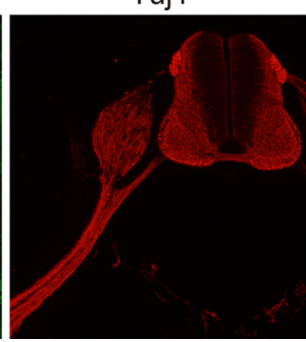

Merge



Merge

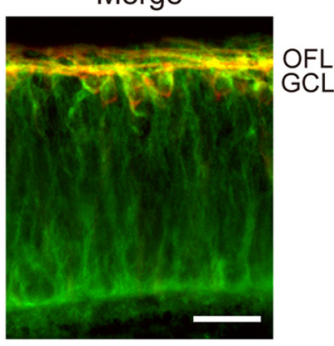

Merge

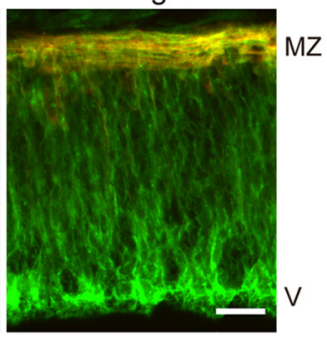

Merge



Figure 2. Expression of APC2 and neuron-specific $\beta$-III tubulin (Tuj1) in the developing chick nervous system. Tuj1 stains cell bodies and axons of postmitotic neurons. $A$, Horizontal section of the head of a stage 25 chick embryo. APC2 is expressed in the nervous system, including the tectum, retina, and optic nerve (ON). Scale bar, $100 \mu \mathrm{m}$. B, Coronal section of the retina of a stage 25 chick embryo. A high level of expression of APC2 is observed in ganglion cell layer (GCL) and optic fiber layer (OFL). Scale bar, 20 $\mu \mathrm{m}$. C, Horizontal section through the tectum of a stage 25 chick embryo. At this stage, tectobulbar neurons extend their axons to the marginal zone (MZ). Mitotic cells in the ventricular zone (V) also express APC2. Scale bar, $20 \mu \mathrm{m}$. D, Coronal section through the trunk of a stage 25 chick embryo. APC2 is distributed in the dorsal root ganglion (DRG) and lateral motor column (LMC) and their axons, the sensory axon (SA) and motor axon (MA). Scale bar, $200 \mu \mathrm{m}$.

was also prepared using pcDNA3.1 at EcoRI/NotI in much the same way: chick APC forward, GAATTCACCATGGCCGCAGCTTCTTATGATCAGTTGTTA; chick APC reverse, GCGGCCGCTAAACAGAAGTCACCAGGTAAGAGCCAG.

The plasmid constructs for knockdown experiments were prepared as described previously (Sakuta et al., 2006; Shintani et al., 2006). The target sequences used for the construction of short hairpin RNAs (shRNA) for $A P C 2$ and enhanced green fluorescent protein $(E G F P)$ were as follows: APC2, GTGCCAGAGCAACTCGCTG for shRNA \#1 (GenBank accession number GQ131429, nucleotide residues 746-764) and GGAGCTGATGGAGGCTCAG for shRNA \#2 (GenBank accession number GQ131429; nucleotide residues 798-816); EGFP, GGAGTTGTC- 
A



B

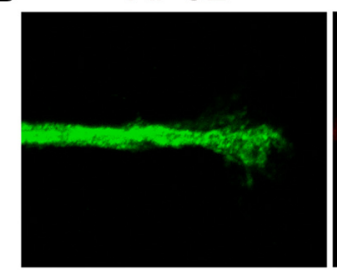

C

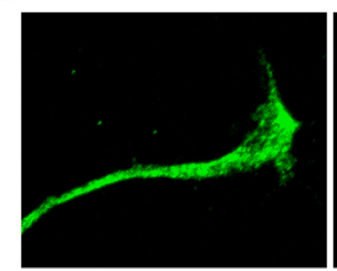

Tubulin



F-actin



APC



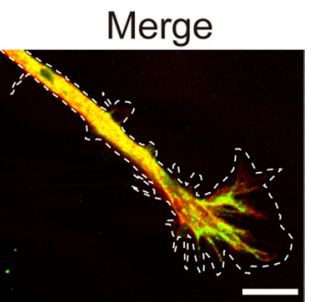

Merge

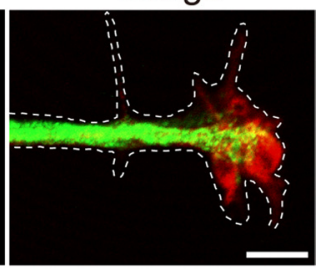

Merge

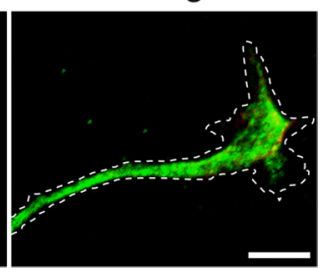

Figure 3. Distribution of $A P C 2$ and cytoskeletal molecules in retinal axons. Growing axons extending from a retinal strip in culture were immunostained and examined with a confocal laser scanning microscope. Dashed lines in the merged images represent outlines of the growth cone traced on differential interference contrast (DIC) images. $A$, Punctate APC 2 immunoreactivity is observed along microtubules in axon shafts and growth cones. $B, A P C 2$ is partially colocalized with F-actin at the central region of growth cones. $C$, APC2 does not colocalize with APC. APC2 showed a more peripheral distribution in growth cones than APC. Scale bars: $A-C, 10 \mu \mathrm{m}$.

CCAATTCTTG (GenBank accession number AF435433; nucleotide residues 28-46).

Cell cultures, transfection, and immunocytochemistry. L cells and B103 cells were grown in DMEM/F-12 medium supplemented with $10 \%$ fetal bovine serum. For the nocodazole treatment, $\mathrm{L}$ cells and B103 cells were incubated for $1 \mathrm{~h}$ in the same medium containing 5 and $1 \mu \mathrm{M}$ nocodazole, respectively. Transfection was performed using LipofectAMINE PLUS (Invitrogen) according to the protocol of the manufacturer. At $24 \mathrm{~h}$ after transfection, cells were fixed with 4\% PFA for 10 min and permeabilized with $0.1 \%$ Triton X-100 in PBS for $5 \mathrm{~min}$. The cells were then incubated for $1 \mathrm{~h}$ in a blocking solution (5\% skim milk in PBS) at room temperature and reacted with primary antibodies for $2 \mathrm{~h}$ at room temperature. After being washed, the cells were treated with Alexaconjugated secondary antibody (Invitrogen) at 1:250 for $1 \mathrm{~h}$ at room temperature. The fluorescent signals obtained were observed with a BX51TRF microscope (Olympus) equipped with a DP-70 digital CCD camera (Olympus) or a Carl Zeiss LSM510 confocal laser microscope, and images were processed using Adobe Photoshop 6.

In ovo electroporation and $1,1^{\prime}$-dioctadecyl-3,3,3',3'-tetramethylindocarbocyanine perchlorate labeling. RCASDC-CU6/APC2-\#1, RCASDC-CU6/APC2-\#2, or RCASDC-CU6/GFP (0.25 $\mu \mathrm{g} / \mu \mathrm{l}$ each) was injected into the right optic vesicles of chick embryos at stage $8-10$, together with pEGFP-N1 $(0.5 \mu \mathrm{g} / \mu \mathrm{l})$, with microglass pipettes. Electroporation and 1,1'-dioctadecyl-3,3,3',3'-tetramethyl-indocarbocyanine perchlorate (DiI) labeling were performed as reported previously (Sakuta et al., 2001, 2006; Shintani et al., 2006). Tecta were cut into lateral and medial halves and then observed with a Carl Zeiss Axioplan 2 microscope, and images obtained were processed using Adobe Photoshop 6.

Immunoblotting. Retinas were lysed in a lysis buffer consisting of 20 mм HEPES, pH 7.4, $120 \mathrm{~mm} \mathrm{NaCl}, 0.1 \%$ SDS, 0.5\% deoxycholate, $1 \%$ Nonidet P-40, 10\% glycerol, $5 \mathrm{~mm}$ EDTA, $50 \mathrm{~mm} \mathrm{NaF}, 0.5 \mathrm{~mm}$ $\mathrm{Na}_{3} \mathrm{VO}_{4}$, and a protease inhibitor mixture $(10 \mu \mathrm{g} / \mathrm{ml}$ leupeptin, 1 $\mu \mathrm{g} / \mathrm{ml}$ pepstatin $\mathrm{A}$, and $1 \mathrm{~mm}$ phenylmethylsulfonyl fluoride). Cell lysates were clarified by centrifugation, and protein concentrations were determined with a BCA microassay kit (Pierce Chemical). Extracts were combined with SDS sample buffer and treated for $15 \mathrm{~min}$ at $75^{\circ} \mathrm{C}$. Ten micrograms of each sample were then subjected to SDS-PAGE. Separated proteins were transferred onto Imobilon-P membranes (Millipore Corporation), stained with specific primary antibodies and peroxidase-linked secondary antibodies (GE Healthcare), and visualized by chemiluminescence using ECL Reagent (GE Healthcare). For the detection, the luminoimage analyzer LAS-3000 (Fujifilm) was used. Signal intensity was quantified by densitometry and analyzed by ANOVA.

Quantitative analysis of microtubules in growth cones. Images of microtubules in growth cones and axon shafts of retinal explants from control and APC2 knockdown embryos were acquired at high resolution (Plan $60 \times$ oil-immersion objective) using a Carl Zeiss Axioplan 2 microscope. Quantification was performed using raw images. For each axon, an area including the growth cone and the distal part of the axon shaft (100 $\mu \mathrm{m}$ from the growth cone) was outlined, and relative immunoreactivity was quantified using NIH ImageJ software. The ratio of fluorescence intensity was calculated for at least 30 growth cones per condition and compared between control and APC2 knockdown growth cones using an ANOVA test.

Flat-mount electroporation of the retina. Electroporation of the chick retina was performed according to our previous report (YuasaKawada et al., 2003; Shintani et al., 2006). Briefly, E6 retinas were flat mounted on a nitrocellulose filter and electroporated (15 times with $15 \mathrm{~V}$ direct current pulses) with an anode and a cathode (5 mm square; Nepa Gene) connected to a CUY21 electroporator (Nepa Gene). To visualize retinal axons, $0.1 \mu \mathrm{g} / \mathrm{ml}$ EGFP-N1 (Clontech) was electroporated. The electroporated retinas were rinsed with HBSS and cut into $275 \mu \mathrm{m}$ strips along the nasal-temporal axis. Retinal strips were then placed on laminin $(20 \mu \mathrm{g} / \mathrm{ml})$-coated dishes and incubated in Ham's F-12 medium containing 8\% FBS, 2\% chick serum, and $0.4 \%$ methylcellulose (Sigma). At various time points $(24,36,48$, and $60 \mathrm{~h}$ ) after the start of culture, we acquired images of EGFP-positive axons with a BX51TRF microscope (Olympus) equipped with a DP-70 digital CCD camera (Olympus) and analyzed axonal growth.

Ephrin-A2-Fc stripe assay. The stripe assay with ephrin-A2-Fc was performed as described previously (Shintani et al., 2006). In short, ephrin-A2-Fc stripes were prepared using a silicon matrix carrying channels $60 \mu \mathrm{m}$ in width with $100 \mu$ l of clustered ephrin-A2-Fc solution $(10 \mu \mathrm{g} / \mathrm{ml})$ containing Alexa594-conjugated transferrin $(25 \mu \mathrm{g} / \mathrm{ml}$; Invitrogen) as a marker. The clustered Fc solution was produced by incubation of Fc proteins $(100 \mu \mathrm{g} / \mathrm{ml})$ with anti-human Ig Fc $(450 \mu \mathrm{g} /$ $\mathrm{ml}$; Rockland Immunochemicals) for $1 \mathrm{~h}$ at room temperature and dilution with conditioned medium. After one wash with HBSS, the second set of lanes were prepared using $80 \mu \mathrm{l}$ of a solution containing clustered Fc (3 $\mu \mathrm{g} / \mathrm{ml})$ with anti-human Fc antibody $(30 \mu \mathrm{g} / \mathrm{ml})$. After $30 \mathrm{~min}$ of incubation, the stripes were washed twice with HBSS, and both lanes were treated with laminin $(20 \mu \mathrm{g} / \mathrm{ml})$ for $2 \mathrm{~h}$.

The E6 retinas electroporated with DNA constructs were rinsed with HBSS and cut into $275 \mu \mathrm{m}$ strips along the nasal-temporal axis. Retinal strips were then placed on the ephrin-A2 stripe individually and incubated in Ham's F-12 medium containing 8\% FBS, 2\% chick serum, and $0.4 \%$ methylcellulose (Sigma) for $2 \mathrm{~d}$. For the nocodazole and taxol experiments, $50 \mathrm{~nm}$ nocodazole or $1 \mathrm{~nm}$ taxol was added to the culture medium, respectively, from the start of culture. The cultures were fixed 
A
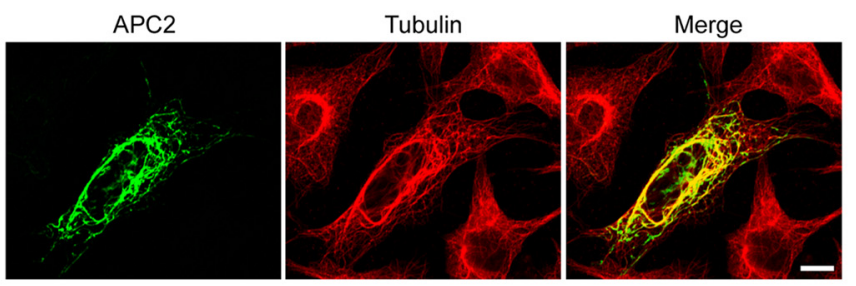

\section{C}

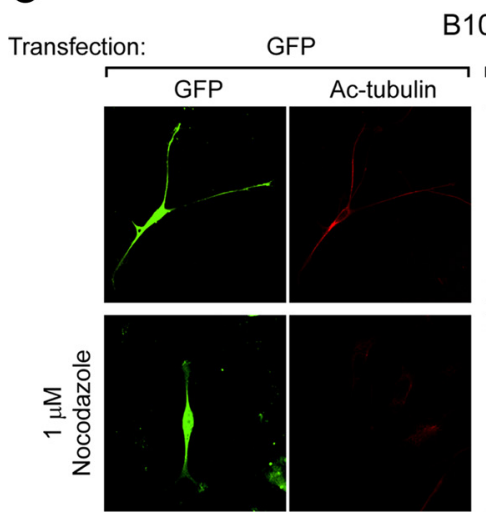

B103



B
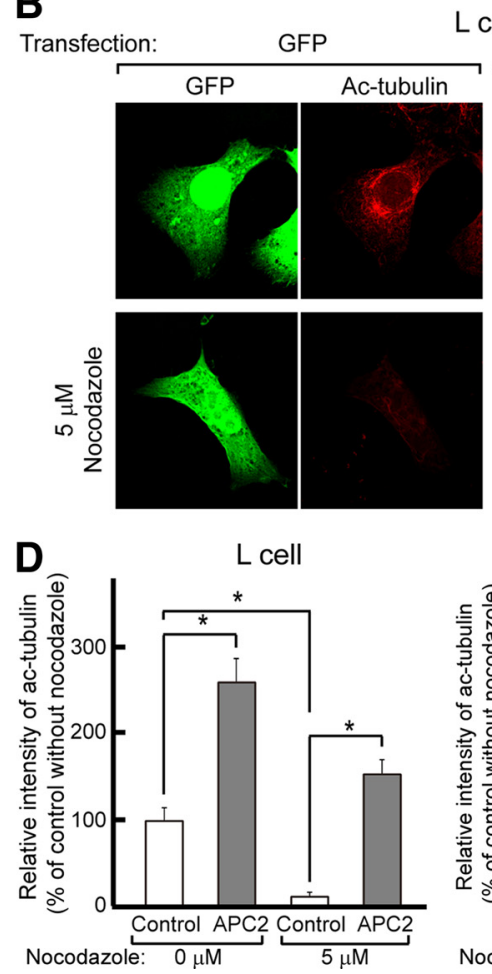

$\mathrm{L}$ cell

APC2
APC2
Ac-tubulin
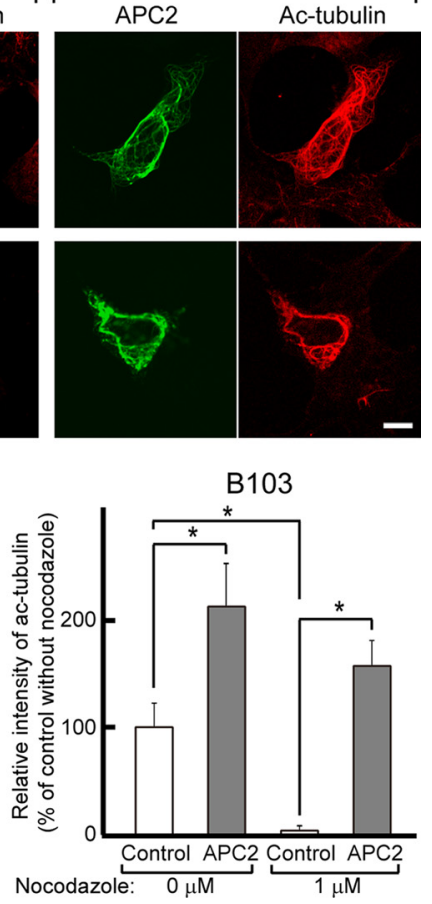

Figure 4. Stabilization of microtubules by APC2. A, Colocalization of APC2 and $\alpha$-tubulin in L cells. Overexpressed APC2 (mouse) was detected by immunostaining using anti-APC2 antibody. Although untransfected L cells express low levels of APC2 mRNA, the endogenous protein product was not detected by immunostaining (or Western blotting; data not shown). Scale bar, $100 \mu \mathrm{m}$. $B, C$, Immunostaining of acetylated tubulin (Ac-tubulin) in GFP- or APC2 (chick)-overexpressing L cells and B103 cells, respectively. In APC2-expressing cells, an increase in acetylated tubulin is observed (right top), and the acetylated tubulin is protected against nocodazole treatment (right bottom). Scale bars, $100 \mu \mathrm{m}$. D, Quantitative analyses of the level of acetylated tubulin. Values are shown as the mean \pm SEM for 50 cells. ${ }^{*} p<0.001$.

with $4 \%$ paraformaldehyde $/ 20 \%$ sucrose/PBS and then stained with antiviral gag antibody (Yuasa et al., 1996) and Alexa488-conjugated secondary antibody. Images were observed with a BX51TRF microscope (Olympus) equipped with a DP-70 digital CCD camera (Olympus), and gag-positive axons were analyzed. Growth preference for each retinal strip was scored on a scale of $0-3$, in which 0 was no bias for either set of lanes and 3 was the strongest bias.

Quantitative analysis of axonal branching on the tectum. The tectum was subdivided into 10 areas along the anteroposterior axis, and numbers of interstitial branches in each area were counted.

\section{Results}

\section{Expression profile of APC2 in the developing chick} nervous system

First, we examined APC2 expression in chick embryos by wholemount in situ hybridization. As shown in Figure $1 B$, restricted expression of APC2 in the nervous system was observed at Hamburger-Hamilton $(\mathrm{HH})$ stage 12 . This expression was further enhanced at $\mathrm{HH}$ stage 15 (Fig. 1C). Conversely, a low level of $A P C$ expression was observed broadly in the whole embryonic body at HH stage 15 (Fig. 1C). Next, we examined the expression of APC2 during the development of the chick retina by section in situ hybridization. A high level of expression of APC2 in the ganglion cell layer was observed in the E6 retina, and this expression pattern continued throughout the developmental stages examined (Fig. 1D).

We further examined the distribution of APC2 protein in the chick nervous system by immunostaining using an antibody highly specific to APC2 (supplemental Fig. 1, available at www.jneurosci.org as supplemental material). Double immunostaining on sections of $\mathrm{HH}$ stage 25 (E5) embryos for APC2 and
Tuj1, a postmitotic neuronal marker, revealed that APC2 was distributed along axons as well as in cell bodies of several types of projecting neurons, including retinal ganglion cells (Fig. 2A,B), tectobulbar neurons (Fig. 2C), motor neurons, and dorsal root ganglion cells (Fig. 2D).

We then examined the distribution of APC2 protein in growing axons using retinal strips prepared from E6 chick embryos. Retinal axons extending from strips were immunostained with anti-APC2 antibody, together with anti- $\alpha$-tubulin or fluorescent phalloidin. Punctate APC2 immunoreactivity was detected in axon shafts and growth cones (Fig. 3). Interestingly, almost all signals of APC2 were observed along microtubules (Fig. 3A): APC2 was abundant in the central region of the growth cone as well as in the axon shaft, in which tubulins were concentrated. Conversely, APC2 little colocalized with filamentous actin (F-actin) except in the central region of growth cones (Fig. $3 B$ ).

Compared with APC2 (Fig. 3C), APC was concentrated in the central domain but showed a more peripheral distribution in the growth cone, suggesting that APC2 and APC differ in function.

\section{APC2 stabilizes microtubules}

When overexpressed in L cell, APC2 was distributed along microtubules (Fig. 4A), which coincided with its pattern of distribution in axons. The colocalization of APC2 and microtubule was similarly observed in COS-7 and HEK293 cells (data not shown), suggesting a role for APC2 in the regulation of microtubule dynamics. We then examined effects of APC2 overexpression on the stability of microtubules in L cells (fibroblasts) and B103 (neuronal cells). There exist at least two pools of microtubules in cells: dynamic microtubules, which exhibit dynamic 
A


$\alpha$-tubulin

GAPDH

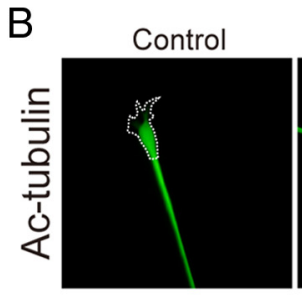

shRNA\#1
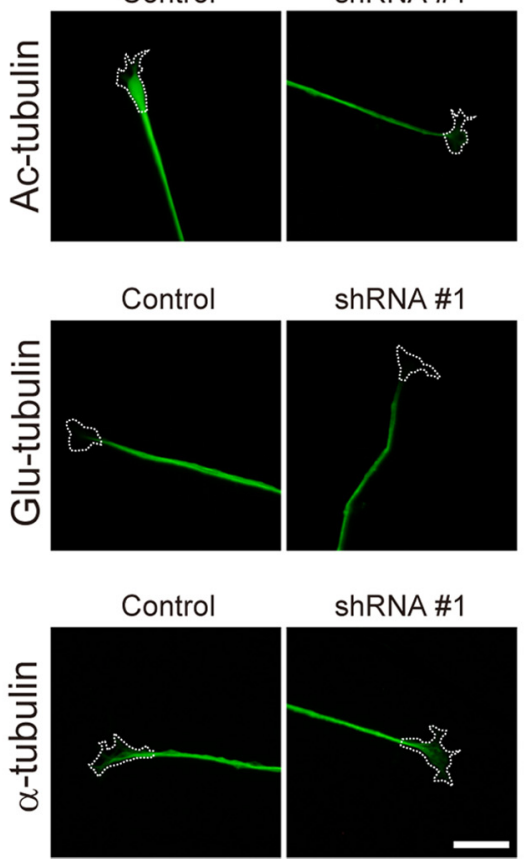

shRNA\#1
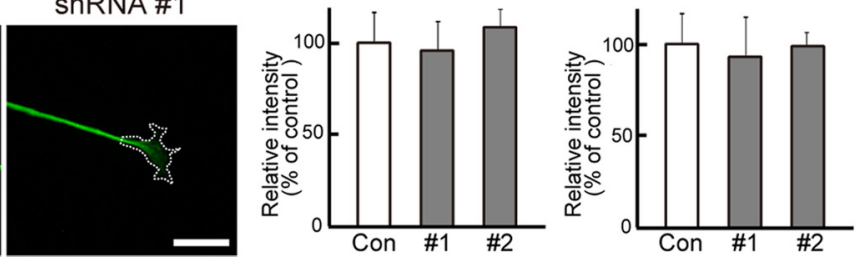

Figure 5. Reduction of microtubule stability in $A P C 2$ knockdown retinas $(\boldsymbol{A})$ and retinal axons $(\boldsymbol{B})$. $\boldsymbol{A}$, Western blot analyses of microtubules in extracts of control ( $C$ on) and $A P C 2$ knockdown retinas. The results of quantitative analyses (right columns) represents the mean \pm SEM for five retinas. Amounts of acetylated (Ac-tubulin) and detyrosinated (Glu-tubulin) tubulins were significantly reduced in $A P C 2$ knockdown retinas. ${ }^{*} p<0.01$. $\boldsymbol{B}$, Immunohistochemical analyses of microtubules in $A P C 2$ knockdown retinal axons. Dashed lines represent outlines of the growth cone traced on DIC images. For each axon, the area including the growth cone and the top distal part of the axon shaft (100 $\mu \mathrm{m}$ from the growth cone) was outlined, and relative immunoreactivity was quantified using NIH ImageJ software. Scale bar, $20 \mu \mathrm{m}$. The results of quantitative analyses (right columns) represent the mean \pm SEM for 30 retinal axons. The intensity of signals for acetylated and detyrosinated tubulins was significantly reduced in $A P C 2$ knockdown retinal axons. ${ }^{*} p<0.01$.

properties with half-lives of 5-10 min (Saxton et al., 1984; Schulze and Kirschner, 1986), and stabilized microtubules, which are rather stable and persist for hours (Saxton et al., 1984; Webster et al., 1987). Microtubules consist of two different tubulins, $\alpha$-tubulin and $\beta$-tubulin. Tubulins that comprise microtubules become posttranslationally modified, and this modification highly correlates with the dynamics of microtubules. One of the best characterized modifications of tubulin is acetylation at lysine 40 of $\alpha$-tubulin, which is considered to be a marker of stabilized microtubules (Bloom, 2004). We therefore examined effects of APC2 overexpression on the stability of microtubules using an antibody against acetylated $\alpha$-tubulin.

When overexpressed in L cells and B103 cells, APC2 colocalized with acetylated tubulin (Fig. $4 B, C$ ). In these cells, the concentration of acetylated tubulin was increased: a quantitative analysis of images of cells stained with anti-acetylated tubulin showed $\sim 2.5$-fold and 2 -fold increases in the APC2-overexpressing L cells and B103 cells, respectively, compared with the control cells (Fig. 4D). We next examined the effect of APC2 overexpression on microtubule stability when cells were treated with the microtubuledestabilizing agent nocodazole. In control cells, the nocodazole treatment disrupted microtubules and yielded a small number of punctates of acetylated tubulin (Fig. $4 B, C)$. In contrast, in APC2-overexpressing cells, the structure of acetylated microtubules remained essentially intact (Fig. $4 B, C)$. Quantitative analysis showed that microtubules were significantly protected from depolymerization by nocodazole in APC2-overexpressing cells (Fig. 4D). These results indicate that APC2 contributes to the stabilization of microtubules.

\section{APC2 knockdown in the retina reduces microtubule stability}

As shown in Figures $1 D$ and $2 B, A P C 2$ is preferentially expressed in the ganglion cell layer in the developing retina. To next examine effects of $A P C 2$ knockdown in the developing retina, $A P C 2$-specific shRNA expression plasmids were introduced into the optic vesicle of chick embryos at $\mathrm{HH}$ stage $8-10$ by in ovo electroporation. We used two shRNA constructs directed toward different target sites of $A P C 2$ and a control shRNA construct for GFP. No gross abnormalities in retinal development were observed in the retinas electroporated with shRNA constructs: control-electroporated and shRNA-electroporated retinas were comparable in the thickness of each layer and cell density (data not shown). Expression levels of APC2 protein in the electroporated retinas were verified at $\mathrm{E} 8$ by immunoblotting for APC2 (Fig. $5 \mathrm{~A}$ ). As expected, misexpression of both of the APC2-specific shRNA constructs significantly decreased APC2 protein levels by $\sim 50 \%$ as a whole in the retina but had no effect on the APC or GAPDH expression level. Thus, our shRNA constructs specifically suppressed APC2 ex- 
pression in the retina. To investigate the microtubule stability in APC2 knockdown retinas, we estimated the amounts of acetylated tubulins and detyrosinated tubulins in the retina by immunoblotting: detyrosinated tubulin (Glu-tubulin), which lacks the C-terminal tyrosine and exposes glutamate (Glu), is another marker of stabilized microtubules. As shown in Figure 5A, protein levels of acetylated and detyrosinated tubulins were reduced by $\sim 70$ and $\sim 50 \%$, respectively, by $A P C 2$ knockdown, although $\alpha$-tubulin levels themselves were not changed: both shRNA constructs (\#1 and \#2) were equally effective.

Next, we examined stabilized microtubules in APC2 knockdown retinal axons. Retinal strips from control and $A P C 2$ knockdown retinas were cocultured in the same dish, and the amounts of acetylated and detyrosinated tubulins in growing axons were quantitatively compared under the same conditions. Expression levels of both acetylated and detyrosinated tubulins were significantly reduced in growth cones and axon shafts of APC2 knockdown retinal axons (Fig. $5 B$ ). Together, microtubules in retinal axons appear to be significantly destabilized by APC2 knockdown.

\section{APC2 knockdown retinal axons exhibit abnormal growth and response to ephrin-A2}

Microtubules and their dynamic rearrangements are essential for the organization and behavior of the axon, as well as the maintenance of axon shape. Therefore, we expected a reduction of microtubule stability in retinal axons of APC2 knockdown embryos to lead to abnormalities in the morphology and behavior of axons. We addressed these points using an in vitro culture system of retinal strips. To investigate individual axons separately, a small proportion of retinal axons were visualized by forced expression of GFP using electroporation to the flat-mount retina (Yuasa-Kawada et al., 2003; Shintani et al., 2006) (Fig. 6A). At various time points after the start of culture $(24,36,48$, and $60 \mathrm{~h}$ ), we acquired images of axons and analyzed axonal behavior.

APC2 knockdown by shRNA did not significantly affect the extension rate of retinal axons: the average speed of growth cone advance of control and APC2 knockdown axons was $0.67 \pm 0.17$ and $0.62 \pm 0.12 \mu \mathrm{m} / \mathrm{h}$, respectively (Fig. 6B). However, APC2 knockdown retinal axons showed more branching than control axons (Fig. $6 C$ ): rates of branching by control and APC2 knockdown retinal axons were $0.42 \pm$ 0.07 and $0.83 \pm 0.12$ branches per millimeter of axon at $60 \mathrm{~h}$ after the start of culture ( $p<0.01$, Mann-Whitney $U$ test $)$. In addi-
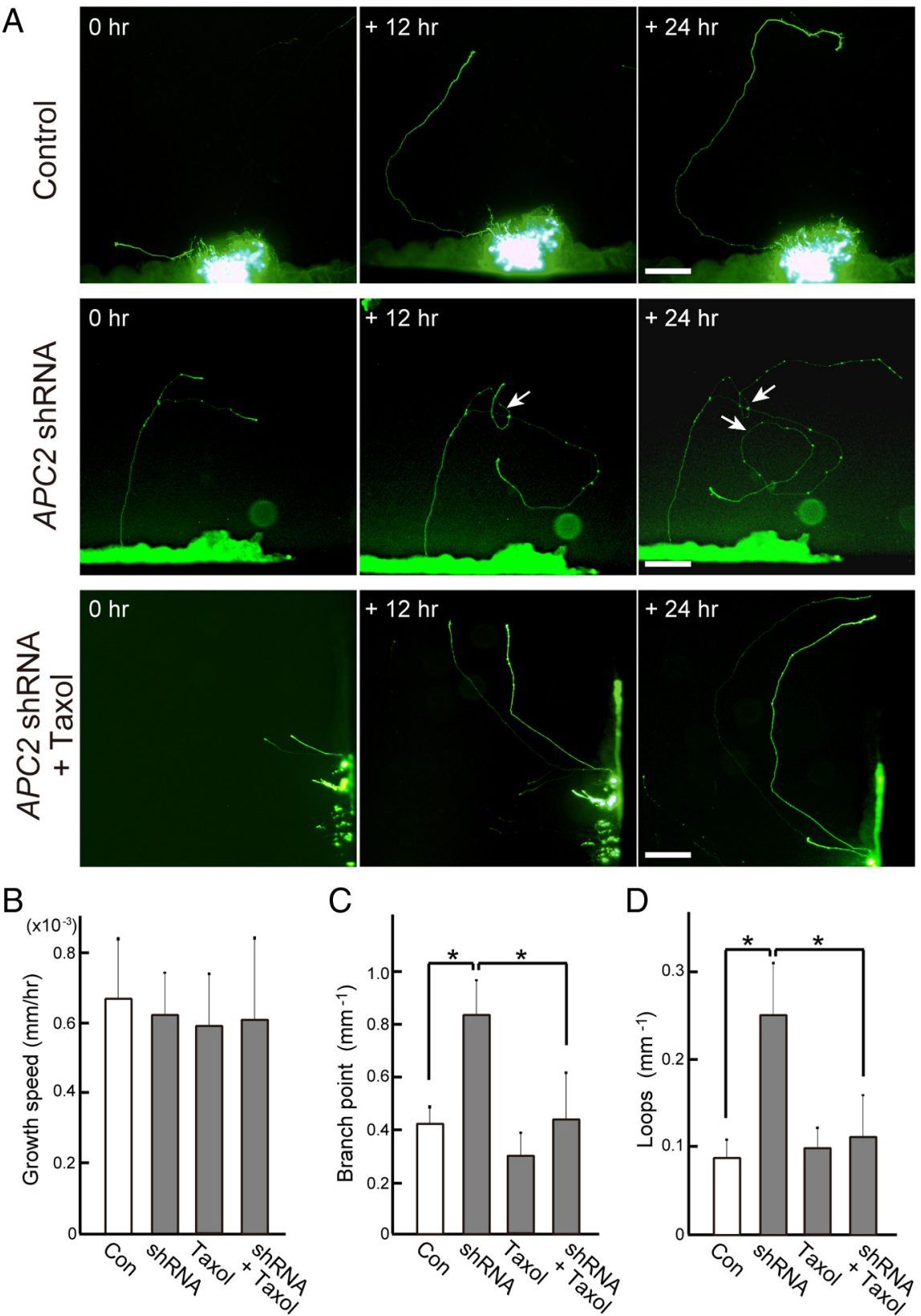

Figure 6. Features of retinal axons of control and $A P C 2$ knockdown embryos. A small population of retinal axons were visualized by forced expression of GFP using flat-mount electroporation. Data by shRNA \#1 are shown. $A$, Behavior of control (top), $A P C 2$ knockdown (middle), and taxol-treated $A P C 2$ knockdown retinal axons in culture. $A P C 2$ knockdown retinal axons often sharply curved back and sometimes made loops (arrows). Scale bar, $250 \mu \mathrm{m}$. $\boldsymbol{B}$, The average speed of growth cone advance of control (Con), APC2 knockdown, taxol-treated control, and taxol-treated $A P C 2$ knockdown retinal axons. No significant difference in growth speed is observed. $C$, Incidence of axon branching of control, $A P C 2$ knockdown, taxol-treated control, and taxol-treated $A P C 2$ knockdown retinal axons. Retinal axons of $A P C 2$ knockdown embryos generated more branches than did control axons. This increased incidence of APC2 knockdown axons was recovered to the control level by taxol treatment. ${ }^{*} p<0.01$. D, Looping incidence of control, $A P C 2$ knockdown, taxol-treated, and taxol-treated $A P C 2$ knockdown retinal axons. Retinal axons of $A P C 2$ knockdown embryos generated more loops than did control axons. This increased incidence of $A P C 2$ knockdown axons was recovered to the control level by taxol treatment. ${ }^{*} p<0.01$.

tion, these axons meandered rather than growing straight, often sharply curved back and sometimes made loops, which was scarcely seen in control axons (Fig. 6D): looping incidences of control and APC2 knockdown retinal axons were $0.09 \pm 0.02$ and $0.25 \pm 0.06$ loops per millimeter of axon at $60 \mathrm{~h}(p<0.01$, Mann-Whitney $U$ test). Interestingly, treatment with taxol (1 $\mathrm{nM})$, a microtubule-stabilizing reagent, rescued these abnormal behaviors of APC2 knockdown retinal axons: growth 
speed $(0.61 \pm 0.22 \mu \mathrm{m} / \mathrm{h})$, incidence of axon branching ( $0.44 \pm 0.18$ branches per millimeter of axon), and axon looping $(0.11 \pm 0.04$ loops per millimeter of axon) (Fig. $6 B-D)$. Here, it should be noted that taxol treatment on control retinal axons did not affect the extension or morphology at this concentration (Fig. $6 B-D$ ).

We next examined the effect of APC2 knockdown on the response of retinal axons to a repulsive molecule, ephrin-A2. Ephrin-A2 is expressed in a posterior high-anterior low gradient in the chick optic tectum and repels temporal axons that bear high levels of EphA receptors but not nasal axons with low levels of EphA receptors (Drescher, 1997; McLaughlin and O'Leary, 2005). Retinal strips were prepared from APC2 knockdown retinas and cultured on stripes that alternately consisted of ephrinA2-Fc (red lanes) and control Fc proteins (dark lanes) (Fig. 7A). Control temporal axons expressing an shRNA toward EGFP strongly preferred to grow in control Fc lanes, not ephrin-A2-Fc lanes (Fig. 7A, top left). Conversely, nasal axons grew in both lanes nonselectively (Fig. $7 B$; N, Control). Surprisingly, when APC2 expression was knocked down by shRNA expression, a large number of the temporal axons turned to grow across the ephrin-A2-Fc lanes like the control nasal axons (Fig. 7A, top right). In contrast, the APC2 knockdown nasal axons continued to grow randomly on the stripes, as did the control nasal axons (Fig. 7B; N, APC2 shRNA). We also examined the effect of nocodazole treatment on the response of retinal axons to ephrin-A2 in the stripe assays. As shown in Figure $7 A$ (bottom left), nocodazole (50 nM)-treated temporal axons showed reduced avoidance toward ephrin-A2-Fc lanes, as did APC2 knockdown temporal axons. Conversely, treatment with taxol ( $1 \mathrm{nM})$ did not exert any effects on the behavior of temporal axons (Fig. $7 B$, Taxol). Importantly, taxol at this concentration rescued the reduced response of APC2 knockdown retinal axons to ephrin-A2 (Fig. 7A, bottom right; $B, A P C 2$ shRNA + Taxol). These results indicate that $A P C 2$ knockdown leads to a reduction in the sensitivity of retinal axons to ephrin-A2 through the destabilization of microtubules.

\section{APC2 is essential for the formation of topographic retinotectal projections}

To examine the function of APC2 in the development of neural projections in vivo, we investigated the effect of APC2 knockdown in retinal axons on the formation of retinotectal projections. The topographic retinotectal projection has been a good model system for studies of how topographic maps form, because the spatial order of neurons is reflected in the order of their axon terminals in the target. Here, retinal ganglion cell axons from the nasal (anterior) retina project to the posterior region of the tectum, whereas axons from the temporal (posterior) retina project to the anterior tectum. The dorsal and ventral retinal axons are connected to the ventral (lateral) and dorsal (medial) tectum, respectively.

We first examined axon trajectories of APC2 knockdown embryos within the retina. Immunostaining of flat-mount E7 retinas with an anti-Tuj1 antibody showed no detectable abnormality in the trajectory of the retinal ganglion cell axon toward the optic fissure and axon fasciculation: APC2 knockdown retinal ganglion cell axons grew straight from their individual sites directly to the optic fissure, as did control axons (supplemental Fig. 2, available at www.jneurosci.org as supplemental material).

To explore the projections of retinal axons to the tectum, we labeled a small number of retinal axons from the right eye with DiI at E11 and analyzed them at E12.5. It is known that almost all
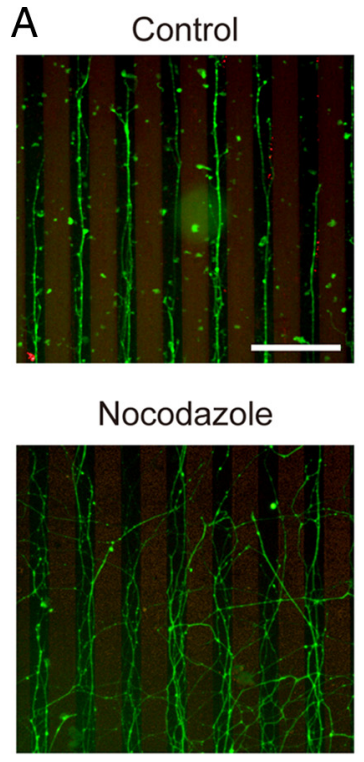

B

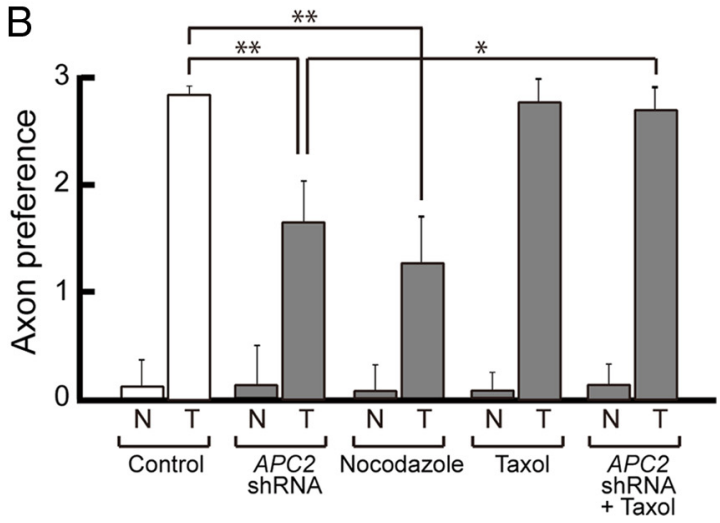

Figure 7. Alteration of the sensitivity of chick retinal axons to ephrin-A2-Fc by $A P C 2$ knockdown. Retinal strips were prepared from control or $A P C 2$ knockdown retinas and cultured on stripes which alternately consisted of ephrin-A2-Fc (red lanes) and control Fc proteins (dark lanes). $\boldsymbol{A}$, Control temporal axons prefer to grow on control Fc-containing lanes (top left). When $A P C 2$ expression was suppressed by shRNA, temporal axons turned to randomly grow in both control Fc and ehprin-A2-Fc lanes (top right). When treated with 50 nм nocodazole, temporal axons turned to randomly grow in both control $\mathrm{Fc}$ and ephrin-A2-Fc lanes (bottom left). When $A P C 2$ knockdown retinal axons were treated with $1 \mathrm{~nm}$ taxol, temporal axons preferred to grow on control Fc-containing lanes as control temporal axons (bottom right). Scale bar, $200 \mu \mathrm{m}$. $\boldsymbol{B}$, Quantification of the effects of $A P C 2$ knockdown or nocodazole treatment on the behavior of retinal axons in the ephrin-A2-Fc stripe assay. The preference of axons for control Fc lanes was scored on an arbitrary scale of 0 (no preference) to 3 (strong preference). Numbers of independent assays for scoring were as follows: control retinal strips, $n=9 ; A P C 2$ knockdown retinal strips, $n=14$; nocodazole-treated retinal strips, $n=10$; taxol-treated $A P C 2$ knockdown retinal strips, $n=10 .{ }^{*} p<0.05 .{ }^{* *} p<0.01$. N, Nasal; T, temporal.

retinal axons cross the midline at the optic chiasm in chick development. We labeled dorsotemporal, dorsonasal, and ventrotemporal axons to analyze their projections (Fig. 8). No ipsilateral projections were observed at E12.5 in the control embryos $(n=24)$ (supplemental Fig. 3, available at www.jneurosci.org as supplemental material). Surprisingly, in embryos whose APC2 expression in the retina was attenuated by APC2-specific shRNA \#1, dorsotemporal, dorsonasal, and ventrotemporal axons all elongated almost equally into the ipsilateral tectum as well as the contralateral tectum (Fig. $8 B, D, F, 8$ of 10,5 of 8 , and 5 of 9 embryos, respectively). These results indicate that half of $A P C 2$ knockdown retinal axons misrouted to the ipsilateral pathway at the chiasm. 
A

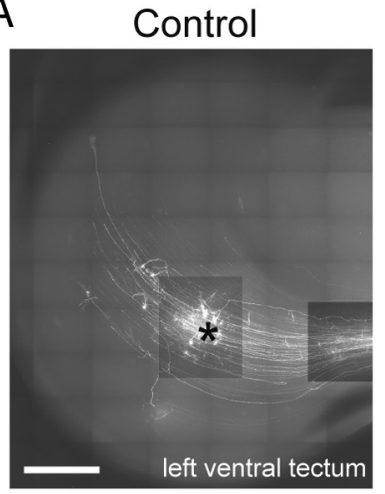

C

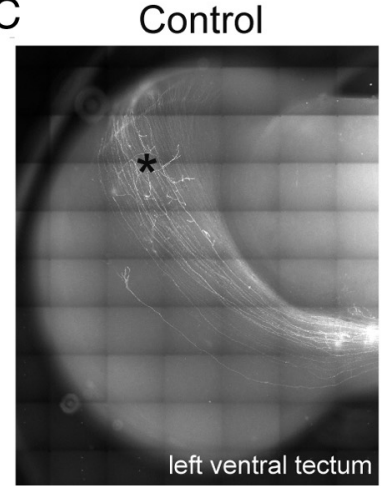

E

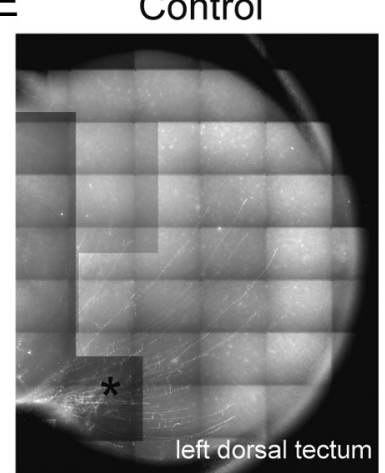

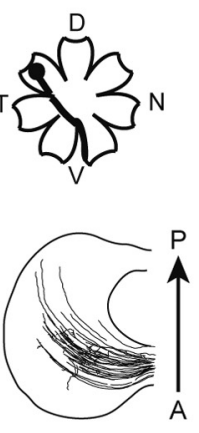

left ventral tectum

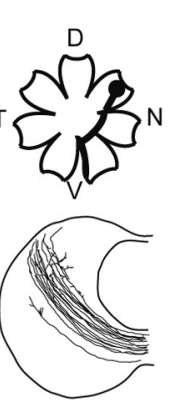

left ventral tectum


left dorsal tectum

B
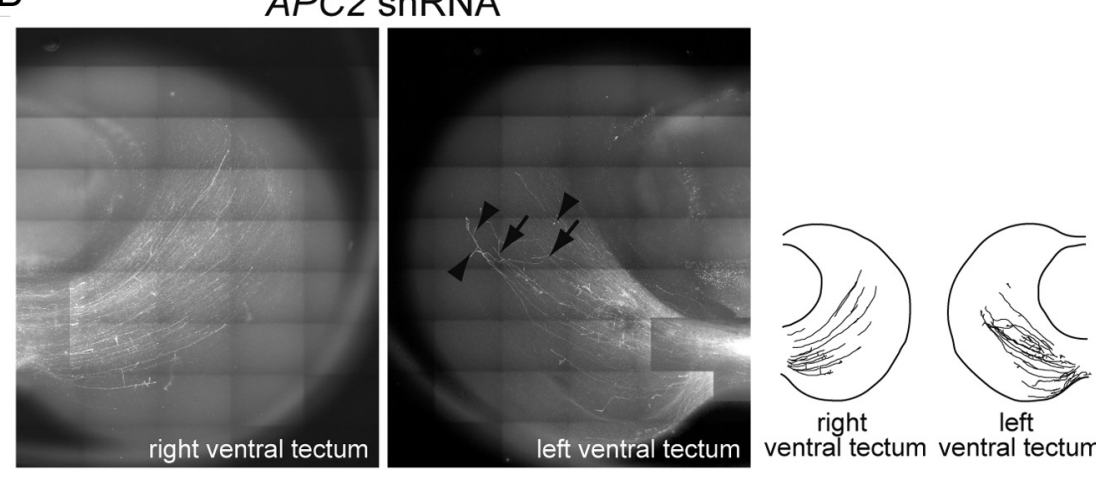

left

ventral tectum ventral tectum
D
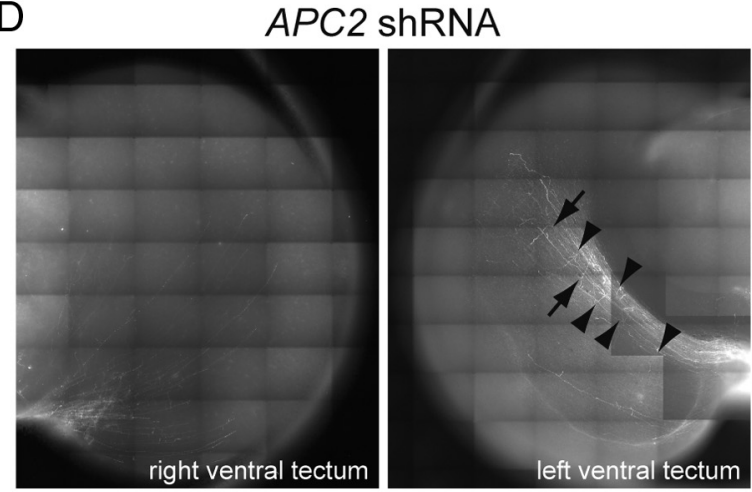



right

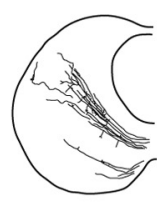

left ventral tectum ventral tectum

\section{F}


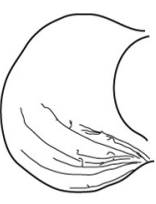

right

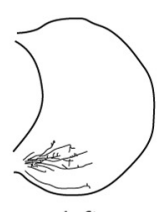

left dorsal tectum dorsal tectum

Figure 8. Retinotectal projections in APC2 knockdown chick embryos at E12.5. After electroporation of an RCAS (replication-competent avian sarcoma retrovirus)-based APC2-specific shRNA expression vector (RCASDC-CU6/APC2 \#1 or \#2) at E1.5 into the right retina, retinal axons were labeled with Dil at E11, and the retina and tecta were analyzed at E12.5. Control embryos were electroporated with a GFP-specific shRNA expression vector (RCASDC-CU6/GFP). $A, C, E$, Typical projection patterns of dorsotemporal, dorsonasal and ventrotemporal retinal axons in control embryos, respectively. In control embryos, axons elongated orderly and parallel to one another in the ventral $(\boldsymbol{A}, \boldsymbol{C})$ or dorsal $(\boldsymbol{E})$ region of the contralateral (left) tectum. Schematic drawings of the photographic images are also shown (bottom right). Posterior is up and anterior is down. In our analysis, no ipsilateral projections were observed in the control embryos (data not shown). Axons formed interstitial branches most often in the vicinity of their future terminal zone (shown by asterisks). The Dil labeling in the right retina is shown (top right). D, Dorsal; $V$, ventral; $N$, nasal; $T$, temporal; $A$, anterior; $P$, posterior. $\boldsymbol{B}, \mathbf{D}, \boldsymbol{F}$, Typical projection patterns of dorsotemporal, dorsonasal, and ventrotemporal retinal axons in $A P C 2$ knockdown embryos, respectively. In $A P C 2$ knockdown embryos, retinal axons elongated equally into the ipsilateral (right) and contralateral (left) tectum. Some axons meandered on the contralateral tectum and were not parallel to one another (arrows). In addition, interstitial branches from axon shafts were diffusely distributed over the tectum (arrowheads). Scale bar, $1 \mathrm{~mm}$.

In the control embryos at E12.5, dorsotemporal axons elongated orderly and parallel to one another in the ventral region of the contralateral (left) tectum (Fig. $8 \mathrm{~A}$ ), and they formed interstitial branches most often within the future terminal zone in the anterior region of the tectum (Fig. $8 \mathrm{~A}$, asterisk). Conversely, in APC2 knockdown embryos, some axons of labeled dorsotemporal axons meandered on the contralateral tectum and were not parallel to one another (Fig. 8 B, arrows: 9 of 10 embryos), and interstitial branches from the axon shafts were diffusely distributed over the tectum (Fig. 8 B, arrowheads: 10 of 10 embryos). Control dorsonasal and ventrotemporal retinal axons extend toward the posterior region of the ventral tectum and the anterior region of the dorsal tectum, respectively, on the contralateral side at E12.5 (Fig. 8C,E). However, dorsonasal and ventrotemporal axons in APC2 knockdown embryos again exhibited meandered extension and abnormal interstitial branches on the tectum (Fig. 8D, F: 7 of 8 and 8 of 9 embryos, respectively). Quantitative analysis of branch distribution on the tectum revealed that branches of APC2 knockdown retinal axons were significantly diffused along the anteroposterior axis compared with the control axons (Fig. 9) $(p<0.01$, Mann-Whitney $U$ test). When APC2 expression was reduced by using another APC2specific shRNA \#2, similar ipsilateral elongation, meandering axons, and a diffuse distribution of interstitial branches were again observed at E12.5 (4 of 8, 7 of 8, and 4 of 8 embryos, respectively; data not shown). 
A


Figure 9. Distribution of interstitial branches of retinal axons on the tectum at E12.5. $\boldsymbol{A}$, The tectum was subdivided into 10 areas along the anteroposterior axis, and numbers of branches in each area were counted. $\boldsymbol{B}-\boldsymbol{D}$, Quantification of branch distributions of dorsotemporal (DT), dorsonasal (DN), and ventrotemporal (VT) retinal axons, respectively. The values are shown as the mean \pm SEM. In APC2 knockdown embryos, interstitial branches from the axon shaft were more diffusely distributed along the anteroposterior axis. A, Anterior; P, posterior.

Then, we labeled retinal axons at E16 and analyzed them at E18, when the formation of retinotectal projections is completed. Intriguingly, the ipsilateral projections observed in APC2 knockdown embryos at E12.5 completely disappeared at this stage. In the control embryos, dorsotemporal and dorsonasal axons converged normally in terminal zones at anterior and posterior positions, respectively, in the ventral region of the contralateral tectum (Fig. 10A, C: $n=10$ and 7 embryos, respectively). Control ventrotemporal axons also converged normally at an anterior position in the dorsal region of the contralateral tectum (Fig. 10E: $n=7$ embryos). Axon segments that overshot the appropriate terminal zone with ectopic branches and arbors thus seemed to be eliminated.

In contrast, in embryos in which APC2 expression in the retina was attenuated by APC2-specific shRNA \#1, dorsotemporal, dorsonasal, and ventrotemporal axons all exhibited abnormal projections (Fig. 10 B, D,F, 9 of 10, 7 of 7, and 6 of 7 embryos, respectively). Many dorsotemporal and ventrotemporal axons overshot the proper region and formed diffuse ectopic terminal zones instead of a correct and small terminal zone (Fig. $10 \mathrm{~B}, \mathrm{~F}$, arrowheads: 8 of 10 and 6 of 7 embryos, respectively). Similarly, APC2 knockdown dorsonasal axons formed diffuse ectopic terminal zones (Fig. 10D, 7 of 7 embryos). In addition, in other $A P C 2$ knockdown embryos, some axons meandered widely on the tectum (Fig. 10B,D,F, arrows: 9 of 10, 7 of 7 , and 6 of 7 embryos, respectively). In embryos in which APC2 expression in the retina was attenuated by APC2-specific shRNA \#2, dorsotemporal axons similarly overshot the proper region and formed diffuse ectopic terminal zones ( 5 of 6 embryos), and meandered widely on the tectum ( 4 of 6 embryos; data not shown). These results clearly indicate that a proper expression level of APC2 is essential for the development of ordered topographic retinotectal projections.

\section{Discussion}

APC2 is highly and preferentially expressed in the developing and adult nervous system compared with APC, which shows ubiquitous expression (Figs. 1, 2) (Nakagawa et al., 1998; Yamanaka et al., 2002). These observations suggest that APC2 has a more important role in the nervous system than APC, but the physiological functions of APC2 remained unclear. In this study, we demonstrated important features of APC2 in the formation of neural projections. First, APC2 associates with microtubules and stabilizes them in growing axons. Second, suppression of APC2 expression in retinal axons leads to abnormal axonal behavior, including a significant loss of response to ephrin-A2 in vitro. Finally, suppression of APC2 expression in retinal axons leads to abnormal guidance at the chiasm and on the tectum, and finally to abnormal terminal formation in vivo. Of note is that these abnormalities were observed when APC2 expression was reduced only by half (Fig. $5 A$ ), implying that the APC2 level plays a critical role in the establishment of neural circuits.

APC2 and APC constitute a protein family. APC has been intensively studied to elucidate its functions in intestinal tumorigenesis, because somatic mutations in the APC gene occur in the majority of sporadic colorectal tumors. Germ-line mutations in $A P C$ are responsible for familial adenomatous polyposis (for review, see Nakamura, 1993). Although APC has been found at sites of cell-cell adhesion in epithelial cells, it also distributes in growth cones in neuronal axons (Shi et al., 2004; Zhou et al., 2004; Koester et al., 2007). APC and APC2 commonly harbor $\mathrm{N}$-terminal dimerization domains, armadillo repeats, $\beta$-cateninbinding 20 aa repeats, and axin-binding SAMP repeats but have less conserved $\mathrm{C}$-terminal regions (Fig. $1 A$ ). APC binds to microtubules directly through its $\mathrm{COOH}$-terminal basic region and indirectly via EB1, a small microtubule-binding protein (Mimori-Kiyosue et al., 2000). APC2 contains neither a microtubule-binding basic region nor a binding site for EB1. So, it has been predicted that APC2 cannot bind to microtubules. In the present study, we showed for the first time that APC2 distributes along microtubules in cultured cells and growing axons and stabilizes microtubules in a manner similar to conventional MAPs. MAPs are considered to be the main modulator of microtubule dynamics (Hirokawa, 1994; Laferrière et al., 1997), and some MAPs have been shown to be important for axon growth (Halpain and Dehmelt, 2006). For example, a complete loss of the $M A P 1 b$ gene results in a lack of the corpus callosum (Meixner et al., 2000). Now, we advocate that APC2 regulates microtubule dynamics by functioning as an MAP-like molecule.

Microtubules are prominent in the central domain (Cdomain) of the growth cone, whereas actin filaments are distributed in the peripheral, motile regions of the growth cone (P-domain). Although actin filaments are well known to be involved in growth cone motility (Smith, 1988), the function of microtubules in growth cones remains less clear. When growth 
cones were treated with drugs such as vinblastin and taxol, which diminish microtubule dynamics by exerting stabilizing effects, directed axon growth in response to inhibitory guidance molecules was lost (Williamson et al., 1996; Challacombe et al., 1997). In addition, focal stabilization of microtubules on one side of the growth cone by taxol induced turning toward the side of application, whereas local microtubule destabilization by nocodazole induce turning away from the side of application (Buck and Zheng, 2002). These results clearly indicate an instructive role of microtubules in that localized stabilization of microtubules underlies the growth cone turning. In the axon shaft, microtubules are bundled together but splay out on entering the P-domain of the growth cone, in which a few of them occasionally extend into the distal, motile domains of lamellipodia, and may even enter the filopodia. Microtubules in the distal region of growth cones exhibit dynamic and characteristic instability with rapid growth and shrinkage (Tanaka and Kirschner, 1991). During growth and navigation of the axon, arrays of microtubules within the growth cone are reorganized and oriented toward the future direction of axon growth (Sabry et al., 1991; Tanaka and Kirschner, 1991, 1995; Tanaka and Sabry, 1995; Suter et al., 1998). Our immunohistochemical colocalization of APC2 with microtubules in the distal region suggests the regulation of microtubule dynamics by APC2 in growth cone navigation. The results of the ephrin-A2 stripe assay and in vivo analyses of retinal projections also support the following view: a disruption of microtubule dynamics in the growth cone caused by APC2 knockdown led to a loss of response of retinal axons to a repulsive guidance molecule, ephrin-A2, in the tectum and resulted in projection-related abnormalities of retinal axons.

APC2 knockdown retinal axons showed drastic guidance errors selectively at the chiasm and on the tectum. In these regions, several guidance molecules have been reported (Thanos and Mey, 2001). Guidance molecules steer growth cones in the proper direction by attracting or repulsing them. Turning to a new direction requires realignment of the cytoskeletal elements (Dent and Gertler, 2003). How does APC2 contribute to growth cone guidance? As mentioned above, local stabilization or destabilization of the microtubules in the growth cone is an essential event for directional axon growth (Buck and Zheng., 2002). Thus, APC2 may be implicated in focal stabilization and destabilization of microtubules in the growth cone in response to external guidance signals. We postulate that local activation or inactivation of APC2 may occur in the growth cone $\boldsymbol{B}, \boldsymbol{D}, \boldsymbol{F})$. Scale bar, $1 \mathrm{~mm}$.
A

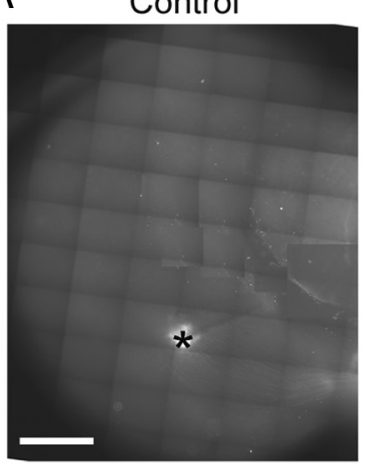

C

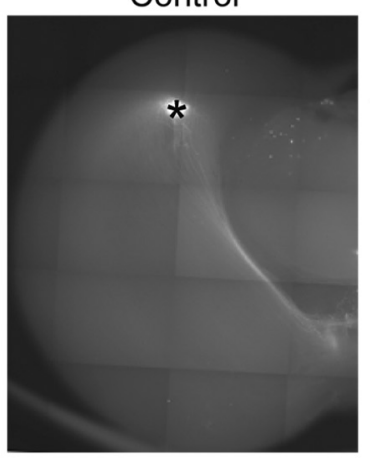

E
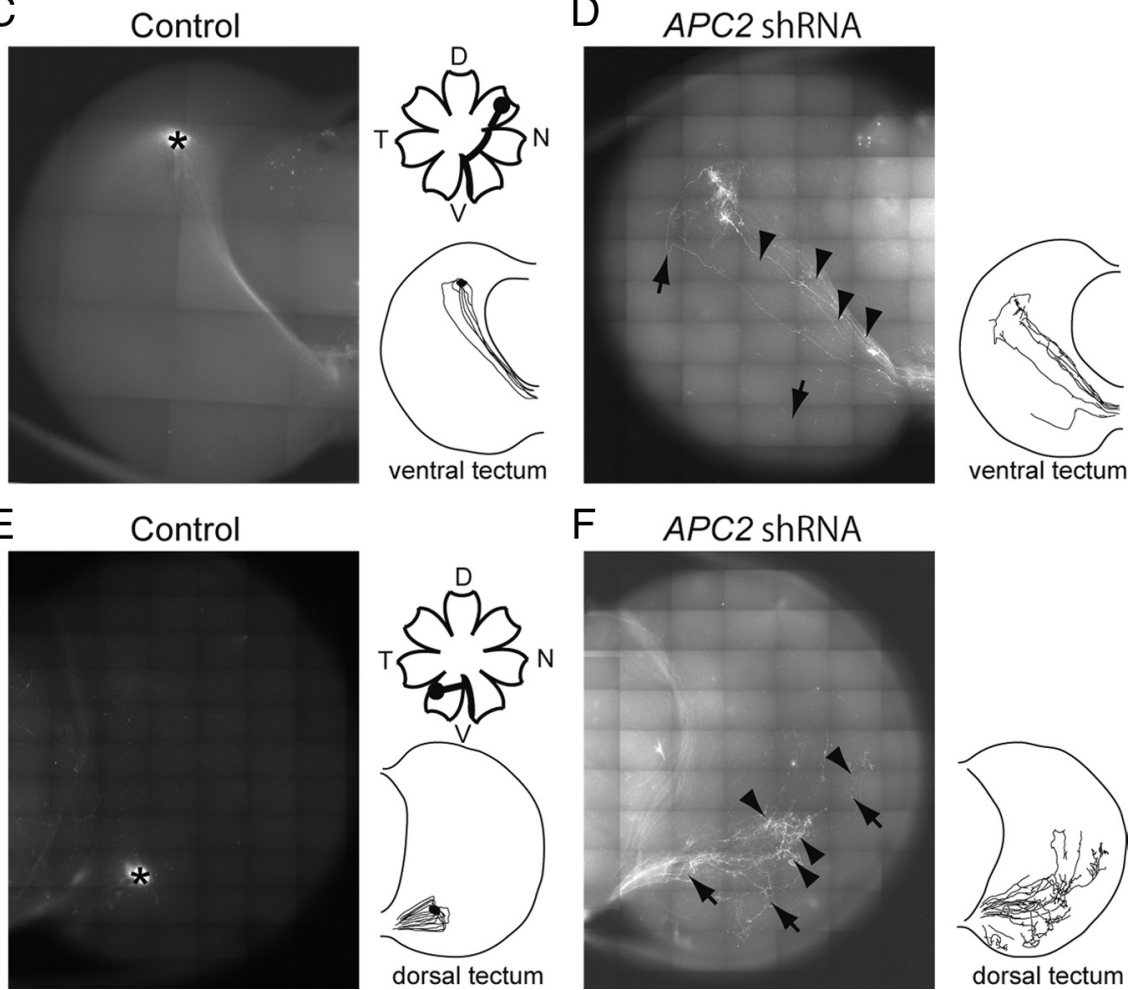

F $\quad A P C 2$ ShRNA
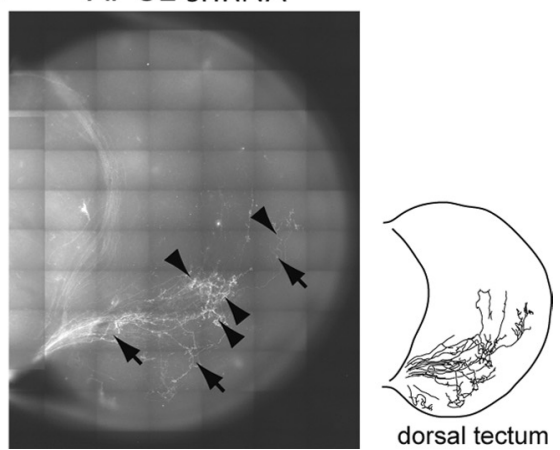

dorsal tectum

Figure 10. Retinotectal projections in $A P C 2$ knockdown chick embryos at E18. After electroporation of an RCAS-based APC2specific shRNA expression vector (RCASDC-CU6/APC2 \#1 or \#2) at E1.5 into the retina, retinal axons were labeled with Dil at E16, and the retina and tecta were analyzed at E18. Control embryos were electroporated with a GFP-specific shRNA expression vector (RCASDC-CU6/GFP). A, C, E, Typical projection patterns of dorsotemporal, dorsonasal, and ventrotemporal retinal axons in control embryos, respectively. The axons normally formed tight terminal zones at anterior $(\boldsymbol{A})$ and posterior $(\boldsymbol{C})$ positions in the ventral region and an anterior position in the dorsal region $(\boldsymbol{E})$ of the contralateral tectum, respectively (shown by asterisks). Schematic drawings of the photographic images are also shown (bottom right). The Dil labeling in the right retina is shown (top right). Posterior is up and anterior is down. D, Dorsal; $\mathrm{V}$, ventral; $\mathrm{N}$, nasal; $\mathrm{T}$, temporal; $\mathrm{A}$, anterior; $\mathrm{P}$, posterior. $\boldsymbol{B}, \mathbf{D}, \boldsymbol{F}$, Typical projection patterns of dorsotemporal, dorsonasal, and ventrotemporal retinal axons in $A P C 2$ knockdown embryos, respectively. In $A P C 2$ knockdown embryos, all axons exhibited abnormal projections. Many dorsotemporal $(\boldsymbol{B})$ and ventrotemporal $(\boldsymbol{F})$ axons overshot the proper region and formed diffuse ectopic terminal zones (arrowheads in $\boldsymbol{B}, \boldsymbol{F}$ ) instead of a proper terminal zone. The dorsonasal axons also formed diffuse ectopic terminal zones (D). Some axons meandered widely on the tectum (arrows in

according to external signals. One possible mechanism for this activation would be phosphorylation of APC2 by a specific kinase(s) locally activated in response to extracellular stimuli, because the microtubule-stabilizing activity of MAPs is reportedly regulated by phosphorylation (Baas and Qiang, 2005).

In addition to the abnormalities in the guidance of retinal axons, APC2 knockdown retinal axons exhibited the ectopic formation of interstitial branches: in APC2 knockdown embryos, interstitial branches from axon shafts were erratically distributed 
over the tectum, whereas normal (control) retinal axons form interstitial branches preferentially in the vicinity of their future terminal zones of the tectum (Figs. 8, 9). Because topographical axon branching on the tectum has been postulated to be regulated by the Eph-ephrin signaling system (O'Leary and McLaughlin, 2005), it is possible that the abnormal branching observed in APC2 knockdown embryos is caused by an attenuated response to ephrin-A2 of retinal axons. The rate of axonal branching is also thought to be regulated by microtubule reorganization (Kalil et al., 2000). Studies with cultured hippocampal neurons suggest that microtubules begin to fragment when and where axonal branches form (Yu et al., 1994). In the fragmentation of microtubules, microtubule-severing proteins such as katanin and spastin are involved, and both are known to be highly expressed in neurons (Ahmad et al., 1999; Errico et al., 2002; Karabay et al., 2004; Yu et al., 2008). Furthermore, MAPs are proposed to protect microtubules from these enzymes (McNally et al., 2002; Qiang et al., 2006). Because APC2 also distributes along microtubules in the axon shaft, there is a possibility that APC2 protects microtubules from the microtubule-severing proteins in the retinal axon. In support of this view, reduction of APC2 enhanced branching when retinal axons were cultured in vitro (Fig. 6).

Elucidation of the functional divergence between APC2 and APC will be an important issue in the future. In parallel with $A P C 2$ knockdown experiments, we tried to perform APC knockdown in the chick retina. However, we could not obtain APC knockdown embryos because $A P C$-specific shRNA expression caused loss of the retinal cells during the development of the retina (our unpublished data). This observation might be consistent with a recent finding made with neuron-specific $A P C$ deficient mice, in which $A P C$ deficiency led to disrupted corticogenesis via a reduction of mitosis in neural tissues (Yokota et al., 2009). Conversely, there was no gross abnormality in cell growth and differentiation in APC2 knockdown chick embryos (data not shown). These differences may imply that APC and APC2 perform different missions in the nervous system. Here it should be noted that there is a difference between these proteins in the cellular expression profile as well as in axons. APC expression in the retina is known to be markedly reduced at E8 (Koester et al., 2007). In contrast, APC2 expression is sustained at a high level throughout the development of the retina (Fig. 1D). Thus, it is conceivable that APC plays an important role in earlier developmental stages than APC2, such as the regulation of neuronal mitosis, differentiation, or axon outgrowth. Conversely, APC2 may play a pivotal role predominantly in the navigation stage of axons.

\section{References}

Ahmad FJ, Yu W, McNally FJ, Baas PW (1999) An essential role for katanin in severing microtubules in the neuron. J Cell Biol 145:305-315.

Baas PW, Qiang L (2005) Neuronal microtubules: when the MAP is the roadblock. Trends Cell Biol 15:183-187.

Bloom K (2004) Microtubule composition: cryptography of dynamic polymers. Proc Natl Acad Sci U S A 101:6839-6840.

Buck KB, Zheng JQ (2002) Growth cone turning induced by direct local modification of microtubule dynamics. J Neurosci 22:9358-9367.

Challacombe JF, Snow DM, Letourneau PC (1997) Dynamic microtubule ends are required for growth cone turning to avoid an inhibitory guidance cue. J Neurosci 17:3085-3095.

Dent EW, Gertler FB (2003) Cytoskeletal dynamics and transport in growth cone motility and axon guidance. Neuron 40:209-227.

Drescher U (1997) The Eph family in the patterning of neural development. Curr Biol 7:R799-R807.

Errico A, Ballabio A, Rugarli EI (2002) Spastin, the protein mutated in au- tosomal dominant hereditary spastic paraplegia, is involved in microtubule dynamics. Hum Mol Genet 11:153-163.

Halpain S, Dehmelt L (2006) The MAP1 family of microtubule-associated proteins. Genome Biol 7:224.1-224.7.

Hamburger V, Hamilton HL (1951) A series of normal stages in the development of the chick embryo. J Morphol 88:49-92.

Hirokawa N (1994) Microtubule organization and dynamics dependent on microtubule-associated proteins. Curr Opin Cell Biol 6:74-81.

Kalil K, Dent EW (2005) Touch and go: guidance cues signal to the growth cone cytoskeleton. Curr Opin Neurobiol 15:521-526.

Kalil K, Szebenyi G, Dent EW (2000) Common mechanisms underlying growth cone guidance and axon branching. J Neurobiol 44:145-158.

Karabay A, Yu W, Solowska JM, Baird DH, Baas PW (2004) Axonal growth is sensitive to the levels of katanin, a protein that severs microtubules. J Neurosci 24:5778-5788.

Koester MP, Müller O, Pollerberg GE (2007) Adenomatous polyposis coli is differentially distributed in growth cones and modulates their steering. J Neurosci 27:12590-12600.

Laferrière NB, MacRae TH, Brown DL (1997) Tubulin synthesis and assembly in differentiating neurons. Biochem Cell Biol 75:103-117.

Matus A (1990) Microtubule-associated proteins and the determination of neuronal form. J Physiol (Paris) 84:134-137.

McLaughlin T, O'Leary DD (2005) Molecular gradients and development of retinotopic maps. Annu Rev Neurosci 28:327-355.

McNally KP, Buster D, McNally FJ (2002) Katanin-mediated microtubule severing can be regulated by multiple mechanisms. Cell Motil Cytoskeleton 53:337-349.

Meixner A, Haverkamp S, Wässle H, Führer S, Thalhammer J, Kropf N, Bittner RE, Lassmann H, Wiche G, Propst F (2000) MAP1B is required for axon guidance and is involved in the development of the central and peripheral nervous system. J Cell Biol 151:1169-1178.

Mimori-Kiyosue Y, Shiina N, Tsukita S (2000) Adenomatous polyposis coli (APC) protein moves along microtubules and concentrates at their growing ends in epithelial cells. J Cell Biol 148:505-518.

Mitchison T, Kirschner M (1988) Cytoskeletal dynamics and nerve growth. Neuron 1:761-772.

Munemitsu S, Souza B, Müller O, Albert I, Rubinfeld B, Polakis P (1994) The APC gene product associates with microtubules in vivo and promotes their assembly in vitro. Cancer Res 54:3676-3681.

Nakagawa H, Murata Y, Koyama K, Fujiyama A, Miyoshi Y, Monden M, Akiyama T, Nakamura Y (1998) Identification of a brain-specific APC homologue, APCL, and its interaction with beta-catenin. Cancer Res 58:5176-5181

Nakamura Y (1993) The role of the adenomatous polyposis coli (APC) gene in human cancers. Adv Cancer Res 62:65-87.

O'Leary DD, McLaughlin T (2005) Mechanisms of retinotopic map development: Ephs, ephrins, and spontaneous correlated retinal activity. Prog Brain Res 147:43-65.

Qiang L, Yu W, Andreadis A, Luo M, Baas PW (2006) Tau protects microtubules in the axon from severing by katanin. J Neurosci 26:3120-3129.

Sabry JH, O'Connor TP, Evans L, Toroian-Raymond A, Kirschner M, Bentley D (1991) Microtubule behavior during guidance of pioneer neuron growth cones in situ. J Cell Biol 115:381-395.

Sakuta H, Suzuki R, Takahashi H, Kato A, Shintani T, Iemura Si, Yamamoto TS, Ueno N, Noda M (2001) Ventroptin: a BMP-4 antagonist expressed in a double-gradient pattern in the retina. Science 293:111-115.

Sakuta H, Takahashi H, Shintani T, Etani K, Aoshima A, Noda M (2006) Role of bone morphogenic protein 2 in retinal patterning and retinotectal projection. J Neurosci 26:10868-10878.

Saxton WM, Stemple DL, Leslie RJ, Salmon ED, Zavortink M, McIntosh JR (1984) Tubulin dynamics in cultured mammalian cells. J Cell Biol 99:2175-2186.

Schulze E, Kirschner M (1986) Microtubule dynamics in interphase cells. J Cell Biol 102:1020-1031.

Shi SH, Cheng T, Jan LY, Jan YN (2004) APC and GSK-3 $\beta$ are involved in $\mathrm{mPar} 3$ targeting to the nascent axon and establishment of neuronal polarity. Curr Biol 14:2025-2032.

Shintani T, Ihara M, Sakuta H, Takahashi H, Watakabe I, Noda M (2006) Eph receptors are negatively controlled by protein tyrosine phosphatase receptor type O. Nat Neurosci 9:761-769.

Smith SJ (1988) Neuronal cytomechanics: the actin-based motility of growth cones. Science 242:708-715. 
Suter DM, Errante LD, Belotserkovsky V, Forscher P (1998) The Ig superfamily cell adhesion molecule, apCAM, mediates growth cone steering by substrate-cytoskeletal coupling. J Cell Biol 141:227-240.

Suzuki R, Shintani T, Sakuta H, Kato A, Ohkawara T, Osumi N, Noda M (2000) Identification of RALDH-3, a novel retinaldehyde dehydrogenase, expressed in the ventral region of the retina. Mech Dev 98:37-50.

Tanaka EM, Kirschner MW (1991) Microtubule behavior in the growth cones of living neurons during axon elongation. J Cell Biol 115:345-363.

Tanaka E, Kirschner MW (1995) The role of microtubules in growth cone turning at substrate boundaries. J Cell Biol 128:127-137.

Tanaka E, Sabry J (1995) Making the connection: cytoskeletal rearrangements during growth cone guidance. Cell 83:171-176.

Thanos S, Mey J (2001) Development of the visual system of the chick. II. Mechanisms of axonal guidance. Brain Res Brain Res Rev 35:205-245.

Yamanaka H, Hashimoto N, Koyama K, Nakagawa H, Nakamura Y, Noguchi K (2002) Expression of Apc2 during mouse development. Brain Res Gene Expr Patterns 1:107-114.

Yokota Y, Kim WY, Chen Y, Wang X, Stanco A, Komuro Y, Snider W, Anton ES (2009) The adenomatous polyposis coli protein is an essential regulator of radial glial polarity and construction of the cerebral cortex. Neuron 61:42-56.
Yu W, Ahmad FJ, Baas PW (1994) Changes in microtubule number and length during axon differentiation. J Neurosci 14:5872-5884.

Yu W, Qiang L, Solowska JM, Karabay A, Korulu S, Baas PW (2008) The microtubule-severing proteins spastin and katanin participate differently in the formation of axonal branches. Mol Biol Cell 19:1485-1498.

Yuasa J, Hirano S, Yamagata M, Noda M (1996) Visual projection map specified by topographic expression of transcription factors in the retina. Nature 382:632-635.

Yuasa-Kawada J, Suzuki R, Kano F, Ohkawara T, Murata M, Noda M (2003) Axonal morphogenesis controlled by antagonistic roles of two CRMP subtypes in microtubule organization. Eur J Neurosci 17:2329-2343.

Webster DR, Gundersen GG, Bulinski JC, Borisy GG (1987) Assembly and turnover of detyrosinated tubulin in vivo. J Cell Biol 105:265-276.

Williamson T, Gordon-Weeks PR, Schachner M, Taylor J (1996) Microtubule reorganization is obligatory for growth cone turning. Proc Natl Acad Sci U S A 93:15221-15226.

Zhou FQ, Zhou J, Dedhar S, Wu YH, Snider WD (2004) NGF-induced axon growth is mediated by localized inactivation of GSK-3beta and functions of the microtubule plus end binding protein APC. Neuron 42:897-912.

Zumbrunn J, Kinoshita K, Hyman AA, Näthke IS (2001) Binding of the adenomatous polyposis coli protein to microtubules increases microtubule stability and is regulated by GSK3 $\beta$ phosphorylation. Curr Biol 11:44-49. 